\title{
PRODUÇÃO DE FORRAGENS DE CANA-DE-AÇÚCAR E FEIJÃO-GUANDU CULTIVADOS EM MONOCULTIVO E CONSÓRCIO ${ }^{1}$
}

\author{
Djalma Silva Pereira²*, Rogério de Paula Lana ${ }^{3}$, Davi Lopes do Carmo ${ }^{4}$, Caryze Cristine Cardoso Sousa ${ }^{5}$, \\ Bianca Amorim Gomide ${ }^{6}$
}

\begin{abstract}
RESUMO - O consócio de culturas tem sido uma prática constante, principalmente pelos pequenos produtores, visando o aproveitamento da área, os benefícios ecológicos e ganhos econômicos. Contudo, deve-se levar em consideração a competição por água, luz e nutrientes que pode ser um fator limitante para o sucesso do consórcio. O objetivo deste trabalho foi avaliar a produção de forragens de cana-de-açúcar e feijão-guandu cultivados em monocultivo e consorciados. O delineamento experimental foi em blocos casualizados, com três tratamentos e cinco repetições. Os tratamentos testados foram: cana-de-açúcar em monocultivo, feijãoguandu em monocultivo e cana-de-açúcar consorciada com feijão-guandu. Os parâmetros avaliados nas plantas de feijão-guandu foram: altura das plantas, número de hastes, massa verde do caule, massa verde das folhas, massa verde da parte aérea, massa seca do caule, massa seca das folhas e massa seca da parte aérea. Na canade-açúcar, foram avaliados os seguintes parâmetros: altura da planta, diâmetro do colmo, número de folhas por planta, largura e comprimento da maior folha, número de plantas por metro linear e produtividade de massa verde. A altura das plantas no segundo corte e o número de hastes no primeiro corte das plantas de feijão-guandu foram superiores no tratamento consorciado com a cana-de-açúcar. Entretanto, as produtividades de massa fresca e seca das folhas foram superiores no tratamento em monocultivo. O número de folhas de cana-de-açúcar foi maior no cultivo consorciado e a produtividade de massa verde no monocultivo. O cultivo consorciado de cana-de-açúcar e feijão-guandu, no espaçamento de $1 \mathrm{~m}$ entre linhas alternadas, não aumenta a oferta de forragem destas culturas.
\end{abstract}

Palavras chave: biomassa, gramínea, leguminosa, Saccharum officinarum.

\section{PRODUCTION OF FORAGE OF SUGARCANE AND PIGEON PEA GROWN IN MONOCULTURE AND CONSORTIUM}

\begin{abstract}
The partnership of cultures has been a constant practice, primarily by small producers, aimed at the exploitation of the area, the environmental benefits and economic gains. However, one must take into consideration the competition for water, light and nutrients that can be a limiting factor to the success of the Consortium. The aim of this study was to evaluate the agronomic performance of sugarcane and pigeon pea grown in monoculture and intercropping for animal feed. The experimental design was randomized blocks, with three treatments and five replications. The treatments tested were: sugarcane in monoculture, pigeon pea in monoculture and sugarcane intercropped with pigeon pea. The parameters evaluated in plants of pigeon pea beans were: height of plants, number of stems, green mass of the stem, green mass of leaves, green mass, dry mass of the stem, leaf dry mass and dry mass of the shoot. In sugarcane were evaluated
\end{abstract}

\footnotetext{
${ }^{1}$ Parte da dissertação de mestrado do primeiro autor, apresentada ao Programa de Pós-Graduação em Agroecologia da Universidade Federal de Viçosa (UFV).

${ }^{2}$ Mestrado em Agroecologia pela (UFV), Viçosa, MG, Brasil. Bolsista FAPEMIG. E-mail: djalma.pereira@ufv.br. Autor para correspondência.

${ }^{3}$ Professor do Departamento de Zootecnia da UFV, bolsista 1B do CNPq.

${ }^{4}$ Pós-doutorando do Programa de Pós-graduação em Agroecologia da UFV, bolsista CAPES.

${ }^{5}$ Mestranda do Programa de Pós-graduação em Zootecnia da Universidade Federal da Grande Dourados (UFGD), bolsista CAPES.

${ }^{6}$ Estudante de graduação em Medicina Veterinária/UFV, bolsista PIBIC/CNPq.
} 


\begin{abstract}
the following parameters: plant height, stem diameter, number of leaves per plant, width and length of the larger sheet, number of plants per linear meter and productivity of green mass. The height of the plants in the second cut and the number of stems in the first cut of the pigeon pea were superior in treatment consorted with sugarcane, however the yields of fresh and dry the leaves were superior in in monoculture. In relation to the sugarcane the number of leaves was higher in the consortium and productivity of green mass in monoculture. Intercropping cultivation of sugarcane and pigeon pea, in $1 \mathrm{~m}$ spacing between alternating rows, does not increase the supply of fodder of these cultures.
\end{abstract}

Keywords: biomass, grass, legumes, Saccharum officinarum.

\section{INTRODUÇÃO}

O Brasil é o maior produtor mundial de cana-deaçúcar (Saccharum officinarum) e domina cerca de dois terços da produção mundial. A cana-de-açúcar representa a terceira maior atividade agrícola do país em termos de área de produção e de valor bruto, perdendo apenas para a soja e o milho (Voltolini et al., 2012). De acordo com os dados da CONAB (2016) a área cultivada de cana-de-açúcar no Brasil, destinada à atividade sucroalcooleira na safra 2016/17, deverá ser de $8.973,2$ ha e produtividade estimada de $76.313 \mathrm{~kg} \mathrm{ha}^{-1}$.

O Estado de Minas Gerais é o terceiro maior produtor de cana-de-açúcar no Brasil, representando uma das culturas de destaque para a alimentação animal, fornecida ao rebanho na forma in natura ou como silagem. Os sistemas produtivos desta cultura caracterizam-se, de modo geral, como sistemas intensivos de produção, com demanda de tecnologias e investimentos financeiros. Considerando o nível tecnológico em que a cultura da cana-de-açúcar é explorada, o investimento e a adoção de sistemas produtivos mais sustentáveis tornam-se relevantes, de maneira que concilie as necessidades econômicas do agricultor com a preservação dos recursos naturais.

O consócio de culturas tem sido uma prática constante, principalmente pelos pequenos produtores, visando o aproveitamento da área e os benefícios ecológicos e econômicos. O cultivo simultâneo de diferentes espécies em uma mesma área pode contribuir para a economia do produtor (Marques et al., 2010), gerando maior renda pela oferta de produtos diferenciados ao longo do ano. Entretanto, é necessário o conhecimento de como determinadas espécies se desenvolvem neste tipo de cultivo. O desempenho de culturas consorciadas depende de vários fatores, com destaque para tipo de cultura e arranjo espacial. Contudo, deve-se levar em consideração a competição por água, luz e nutrientes, que pode ser um fator limitante para o sucesso do consórcio, podendo prejudicar o desenvolvimento e, consequentemente, a produtividade da cultura (Pariz et al., 2011).

A introdução de leguminosas nas pastagens com gramíneas, através do consórcio, promove incrementos na produção animal pela qualidade e quantidade da forragem em oferta, pela participação da leguminosa na dieta animal e pelos efeitos indiretos relacionados com a fixação biológica de nitrogênio e seu repasse ao ecossistema da pastagem (Neres et al., 2012). Para Barcellos et al. (2008), a adoção de leguminosas na formação de pastagens, em consórcio ou em monocultivo, é orientada pela escolha do cultivar mais adequado às condições ambientais, à natureza da exploração, à capacidade de intervenção e à disponibilidade de recursos. O consórcio entre gramíneas e leguminosas visa atender à demanda por alternativas à adubação nitrogenada e, além disso, outros benefícios, como melhorias dos atributos químicos, físicos e biológicos do solo (Prellwitz \& Coelho, 2011).

Dentre as leguminosas forrageiras, o feijão-guandu (Cajanus cajan) destaca-se devido aos seus múltiplos usos, além de servir como fonte de proteína para a alimentação animal, desempenha importante papel na ciclagem e fornecimento de nutrientes, principalmente nitrogênio (Azevedo et al., 2007). Esta cultura consiste em uma importante fonte de proteína em muitos países dos trópicos e subtrópicos, tolerante a condições adversas, como baixa fertilidade do solo e à seca (Provazi et al., 2007). Devido ao seu alto valor nutritivo, é uma cultura utilizada na alimentação de animais, como gado de leite e/ou corte, aves e suínos (Azevedo et al., 2007).

Partindo do pressuposto que o consórcio de canade-açúcar com feijão-guandu pode favorecer incremento na produtividade dessas culturas, objetivou-se avaliar a produção de forragens de cana-de-açúcar (Saccharum officinarum) e feijão-guandu (Cajanus cajan) cultivados em monocultivo e consorciados. 


\section{MATERIALE MÉTODOS}

O experimento foi conduzido entre novembro de 2015 e julho de 2016, no sítio Boa Vista, distrito de Cachoeira de Santa Cruz, Viçosa-MG, pertencente à Universidade Federal de Viçosa (UFV). O local está na região da Zona da Mata de Minas Gerais e tem como coordenadas geográficas a posição $20^{\circ} 44^{\prime} 40^{\prime \prime}$ de latitude Sul e 42 $46^{\prime} 11$ " de longitude Oeste de Greenwich e altitude de $651 \mathrm{~m}$. O clima é do tipo Cwa (mesotérmico), segundo classificação de Köppen, com duas estações bem definidas, constituídas de verão quente e úmido e inverno frio e seco. A precipitação pluviométrica média é de $1.341 \mathrm{~mm}$ anuais. As médias de temperaturas máxima e mínima são 26,1 e $14,0^{\circ} \mathrm{C}$, respectivamente (UFV, 1997). Na Figura 1 encontram-se os dados climáticos do município de Viçosa, MG, computados durante o período experimental (UFV, 2015, 2016).

O delineamento experimental foi em blocos casualizados (DBC), com três tratamentos e cinco repetições, totalizando 15 parcelas de $20 \mathrm{~m}^{2}$. Os tratamentos testados foram: cana-de-açúcar em monocultivo; feijãoguandu em monocultivo e consórcio de cana-de-açúcar e feijão-guandu.

A área experimental compreendeu a uma área de pastagem que foi cultivada com capim Urochloa decumbens por mais de 10 anos. Para a instalação do experimento procedeu-se o preparo convencional da área (aração e gradagem na profundidade de 0,3 m), seguindo-se o sulcamento nos espaçamentos

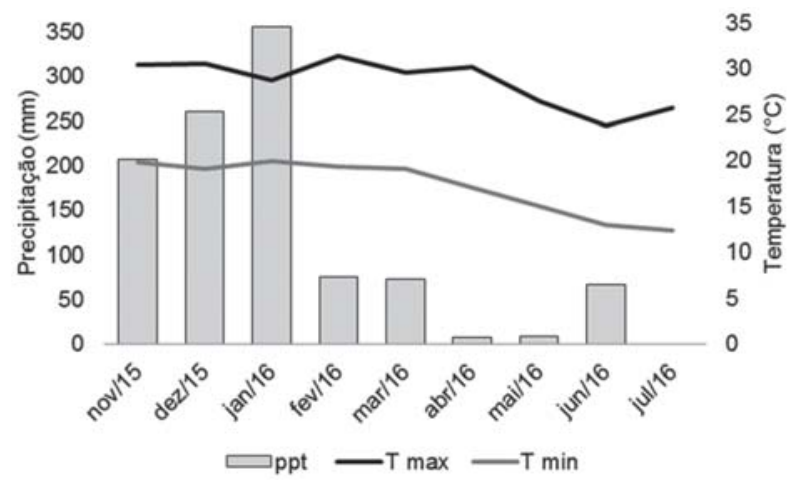

Figura 1 - Dados da precipitação (ppt), da temperatura máxima (T max) e temperatura mínima (T min), registrados no município de Viçosa-MG, durante o período de novembro de 2015 a julho de 2016. determinados. Posteriormente, a área foi dividida em 15 parcelas de $20 \mathrm{~m}^{2}$. Dentre as práticas de manejo, foi realizada a capina manual das plantas espontâneas, quando necessário, e não foi utilizada irrigação na área experimental.

O solo apresentou as seguintes características químicas na profundidade de 0-0,2 m: $\mathrm{Ca}=3,9 \mathrm{cmol}_{\mathrm{c}}$ $\mathrm{dm}^{-3} ; \mathrm{Mg}=1,6 \mathrm{cmol}_{\mathrm{c}} \mathrm{dm}^{-3} ; \mathrm{K}=64,0 \mathrm{mg} \mathrm{dm}^{-3} ; \mathrm{Al}=0,0$ $\mathrm{cmol}_{\mathrm{c}} \mathrm{dm}^{-3} ; \mathrm{H}+\mathrm{Al}=2,6 \mathrm{cmol}_{\mathrm{c}} \mathrm{dm}^{-3} ; \mathrm{P}=9,2 \mathrm{mg} \mathrm{dm}^{-3} ; \mathrm{pH}$ $\mathrm{H}_{2} \mathrm{O}=5,7 ; \mathrm{t}=5,7 \mathrm{cmol}_{\mathrm{c}} \mathrm{dm}-3 ; \mathrm{T}=8,3 \mathrm{cmol}_{\mathrm{c}} \mathrm{dm}^{-3} ; \mathrm{SB}=$ $5,7 \mathrm{cmol}_{\mathrm{c}} \mathrm{dm}^{-3} ; \mathrm{V}=68,7 \%$ e $\mathrm{MO}=1,2 \mathrm{dag} \mathrm{kg}-1$. De forma complementar realizou-se adubação com cama de frango, antes do plantio, na dose de $6 \mathrm{t} \mathrm{ha}^{-1}$, no sulco. A cama de frango utilizada apresentou as seguintes características químicas: $\mathrm{N}=3,48 \% ; \mathrm{P}=0,96 \% ; \mathrm{K}=2,56 \%$; $\mathrm{Ca}=1,88 \% ; \mathrm{Mg}=0,48 \% ; \mathrm{S}=0,45 \% ; \mathrm{CO}=21,5 \% ; \mathrm{C} / \mathrm{N}=$ 6,18; $\mathrm{pH} \mathrm{H}_{2} \mathrm{O}=7,2$; Matéria seca= 43,3\%.

O plantio foi realizado no mês de novembro de 2015, início da estação chuvosa. Para o cultivo de canade-açúcar o plantio foi realizado manualmente, utilizandose a variedade RB86-7515, em espaçamento de 1,0 m entre linhas e duas fileiras de cana por sulco, picada em tamanhos de 0,2-0,3 m dentro do sulco com uso de um facão. O feijão-guandu, cultivar IAC-Fava Larga, foi semeado no espaçamento de 1,0 m entre linhas e $0,2 \mathrm{~m}$ entre plantas. No consórcio, o plantio foi feito em linhas alternadas, em uma linha foi plantado feijãoguandu e na outra linha a cana-de-açúcar, no espaçamento de 1,0 m entre linhas.

Aos três meses após o plantio (fevereiro/2016), foram realizadas as avaliações de altura das plantas (AP), diâmetro do caule (DC) e número de hastes (NH) de plantas de feijão-guandu. Em seguida as plantas foram cortadas na altura de 0,6 $\mathrm{m}$ do nível do solo, nesta ocasião o material cortado (folhas e hastes) foi depositado sobre o solo, a fim de favorecer a liberação de nutrientes ao solo.

Três meses após o primeiro corte (maio/2016), ou seja, seis meses após o plantio foram avaliadas as seguintes características agronômicas das plantas de feijão-guandu: altura das plantas (AP), número de hastes $(\mathrm{NH})$, massa verde do caule (MVC), massa verde das folhas (MVF), massa verde da parte aérea (MVPA), massa seca do caule (MSC), massa seca das folhas (MSF) e massa seca da parte aérea (MSPA). A AP foi determinada por meio de medições utilizando-se régua graduada do colo até o ápice; o DC foi medido utilizando- 
se paquímetro universal na altura do corte $(0,6 \mathrm{~m})$, medido apenas no primeiro corte; $\mathrm{o}$ NH foi determinado contandose o número de ramificações no caule principal. Posteriormente, as plantas foram cortadas na altura de $0,6 \mathrm{~m}$ do solo e pesadas para a determinação da MVC, MVF e MVPA. Em seguida, o material coletado permaneceu em estufa de circulação forçada a $65^{\circ} \mathrm{C}$ por 48 h para a determinação da MSC, MSF e MSPA. A produtividade da massa verde e da massa seca das plantas de feijão-guandu foi determinada considerandose a população final de 50.000 plantas ha $^{-1}$.

Aos oito meses após o plantio (julho/2016), foram feitas as avaliações agronômicas da cana-de-açúcar. Os parâmetros avaliados foram: altura da planta (AP), diâmetro do colmo (DC), número de folhas por planta (NF), largura da maior folha (LF) e comprimento da maior folha (CF), número de plantas por metro linear (NP) e produtividade de massa verde (MV). A AP foi medida a partir do solo até a lígula das folhas mais altas com uso de uma fita métrica; o DC foi mensurado com o uso de um paquímetro universal; contou-se o número de folhas por planta e posteriormente mediuse a largura e comprimento da maior folha com o uso de uma fita métrica. Para a avaliação das plantas desconsiderou-se as extremidades das parcelas (bordadura) e avaliou-se 5 plantas por parcela.

Em julho de 2016, após oito meses de cultivo, foram coletadas amostras de solos, na profundidade 0-0,2 $\mathrm{m}$, para as seguintes análises: $\mathrm{pH}$ em água, teores de $\mathrm{Ca}^{2+}, \mathrm{Mg}^{2+}, \mathrm{K}^{+}, \mathrm{Al}^{3+}, \mathrm{H}+\mathrm{Al}, \mathrm{P}$ e $\mathrm{MO}$, t, T e V de acordo com a metodologia compilada à EMBRAPA (1997).

Os dados obtidos foram submetidos à análise de variância (ANOVA) e, havendo significância, as médias de tratamentos foram comparadas pelo teste de Tukey ao nível de 5 \% de significância, utilizando o programa de estatística SISVAR (Ferreira, 2014).

\section{RESULTADOS E DISCUSSÃO}

A altura das plantas de feijão-guandu no primeiro corte (AP1), o diâmetro do caule (DC) e o número de hastes no segundo corte (NH2) não apresentaram diferença significativa, enquanto que a altura das plantas no segundo corte (AP2) e o número de hastes no primeiro (NH1) diferiram (Tabela 1). No segundo corte, a altura das plantas de feijão-guandu consorciado com cana-de-açúcar foi superior à do feijão-guandu em monocultivo. Observa-se redução média de $15 \%$ da altura das plantas do primeiro para o segundo corte.

A AP é uma importante característica a ser considerada, pois determinadas populações de feijãoguandu têm porte arbóreo e podem tornar-se inadequadas para uso como planta forrageira (Godoy et al., 2005). Para Provazi et al. (2007) o desejável é que as plantas para utilização como forrageira sejam relativamente baixas (aproximadamente $0,5 \mathrm{~m}$ de altura) para facilitar o consumo pelos animais. No presente estudo, a AP foi inviável para o pastejo de animais, sendo recomendado o corte para consumo in natura ou para produção de silagem.

O valor encontrado para o DC é considerado alto, não sendo o desejável para a alimentação animal em pastejo. De acordo com Provazi et al. (2007) caules com diâmetros menores facilitam o acesso do animal à planta.

Para o NH, observou-se que, no primeiro corte (NH1), o tratamento de feijão-guandu consorciado obteve média maior; já no segundo corte não houve efeito dos tratamentos no NH. Houve redução de $81 \%$ do primeiro corte para o segundo no $\mathrm{NH}$. Essa redução brusca se deve, não somente pela redução da AP, mas, principalmente, porque as hastes surgem a partir do caule principal. Após o corte de $0,6 \mathrm{~m}$, na altura do nível do solo, o caule principal não se desenvolve mais, havendo apenas o desenvolvimento dos caules secundários. Do ponto de vista forrageiro, é interessante que haja maior $\mathrm{NH}$, isso porque esses ramos geralmente são mais finos, o que possibilita maior consumo e qualidade da forragem (Provazi et al., 2007).

AMVC, MVPA, MSC e MSPA das plantas de feijãoguandu não apresentaram diferença significativa entre os tratamentos, enquanto a MFV e MSF diferiram de forma significativa (Tabela 2).

A MVF e a MSF foram superiores para o feijãoguandu em monocultivo, justificando-se pelo fato das plantas em monocultivo possuírem um maior estande final de plantas por hectare. Do ponto de vista forrageiro, a produção de massa seca de folhas é provavelmente o dado mais importante a ser analisado (Godoy et al., 2005).

Para as características AP e DC da cana-de-açúcar não houve efeito do consórcio com o feijão-guandu (Tabela 3). Resultados semelhantes foram observados por Ambrosano et al. (2013), que avaliaram o desempenho 
Tabela 1 - Valores médios de altura da planta no primeiro (AP1) e no segundo corte (AP2), diâmetro do caule (DC) e número de hastes no primeiro (NH1) e no segundo corte (NH2) de feijão-guandu cultivado em monocultivo e consorciado com cana-de-açúcar

\begin{tabular}{|c|c|c|c|c|c|}
\hline Tratamento & AP1 & AP2 & DC & NH1 & NH2 \\
\hline & 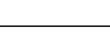 & 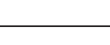 & $\mathrm{mm}$ & 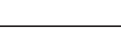 & 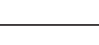 \\
\hline Guandu & 2,11 a & $1,69 \mathrm{~b}$ & 14,71 a & $37,04 \mathrm{~b}$ & 8,00 a \\
\hline Guandu consorciado & 2,18 a & 1,95 a & 16,45 a & 41,16 a & $7,20 \mathrm{a}$ \\
\hline Média Geral & 2,14 & 1,82 & 15,58 & 39,1 & 7,60 \\
\hline CV (\%) & 5,56 & 7,18 & 6,58 & 3,54 & 10,55 \\
\hline
\end{tabular}

Médias seguidas pela mesma letra na coluna não diferem entre si pelo teste Tukey ao nível de 5\% de probabilidade. CV - coeficiente de variação.

Tabela 2 - Valores médios de massa verde do caule (MVC), massa verde da folha (MFV), massa verde da parte aérea (MVPA), massa seca do caule (MSC), massa seca da folha (MSF) e massa seca da parte aérea (MSPA) de feijão-guandu cultivado em monocultivo e consorciado com cana-de-açúcar

\begin{tabular}{lcccccc}
\hline Tratamento & MVC & MVF & MVPA & MSC & MSF \\
\cline { 2 - 4 } & \multicolumn{7}{c}{ t ha $^{-1}$} & & & \\
\cline { 2 - 5 } Guandu & $8,71 \mathrm{a}$ & $7,22 \mathrm{a}$ & $15,93 \mathrm{a}$ & $3,66 \mathrm{a}$ & $2,61 \mathrm{a}$ & $6,28 \mathrm{a}$ \\
Guandu consorciado & $5,59 \mathrm{a}$ & $2,97 \mathrm{~b}$ & $8,56 \mathrm{a}$ & $1,51 \mathrm{a}$ & $1,11 \mathrm{~b}$ & $2,61 \mathrm{a}$ \\
Média Geral & 7,15 & 5,1 & 12,25 & 2,58 & 1,86 & 4,44 \\
CV $(\%)$ & 40,74 & 38,41 & 37,67 & 55,76 & 39,55 & 48,00 \\
\hline
\end{tabular}

Médias seguidas pela mesma letra na coluna não diferem entre si pelo teste Tukey ao nível de 5\% de probabilidade. CV - coeficiente de variação.

Tabela 3 - Características agronômicas da cana-de-açúcar aos oito meses de idade cultivada em monocultivo e consorciada com feijão-guandu

\begin{tabular}{|c|c|c|c|c|c|c|c|}
\hline Tratamento & AP & DC & NF & LF & $\mathrm{CF}$ & NP & MV \\
\hline & $\mathrm{m}$ & $\mathrm{mm}$ & $\mathrm{n}^{\mathrm{o}}$ & 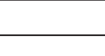 & 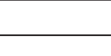 & $\mathrm{m}$ linear $^{-1}$ & $\mathrm{t} \mathrm{ha}^{-1}$ \\
\hline Cana & $1,71 \mathrm{a}$ & 28,16 a & $6,90 \mathrm{~b}$ & 5,46 a & 116 a & 12,40 a & $116,00 \mathrm{a}$ \\
\hline Cana consorciada & 2,65 a & 28,96 a & 7,56 a & 5,56 a & $117 \mathrm{a}$ & 12,16 a & $62,33 \mathrm{~b}$ \\
\hline Média Geral & 1,68 & 28,56 & 7,23 & 5,51 & 117 & 12,28 & 89,17 \\
\hline CV (\%) & 3,1 & 3,28 & 5,16 & 7,53 & 7,02 & 16,41 & 11,28 \\
\hline
\end{tabular}

Médias seguidas pela mesma letra na coluna não diferem entre si pelo teste Tukey ao nível de $5 \%$ de probabilidade. AP= altura da planta, $\mathrm{DC}=$ diâmetro do colmo, $\mathrm{NF}=$ número de folhas, $\mathrm{LF}=$ largura da folha, $\mathrm{CF}=$ comprimento da folha, $\mathrm{NP}=$ número de plantas, $\mathrm{MV}=$ massa verde, $\mathrm{CV}=$ coeficiente de variação.

de cana-de-açúcar em consórcio com diferentes leguminosas, dentre elas o guandu anão. Os autores constataram que as diferentes espécies de leguminosas não influenciaram a altura da planta e o diâmetro de colmos, quando comparadas com o cultivo da canade-açúcar em monocultivo. Em contrapartida, Prellwitz e Coelho (2011) observaram que as plantas de canade-açúcar em consórcio com a Crotalaria juncea obtiveram os maiores valores de altura e foram superiores aos dos tratamentos em monocultivo.
Em relação ao NF observou-se que o consórcio da cana-de-açúcar com o feijão-guandu proporcionou maior média (Tabela 3). O cultivo consorciado entre gramínea e leguminosa pode trazer vários benefícios para as plantas. Em relação às gramíneas, o maior benefício está no fornecimento de nitrogênio (N) por meio da fixação biológica de nitrogênio (FBN) realizada pelas leguminosas. Calvo et al. (2010) constataram que a consorciação de sorgo (Sorghum bicolor L.) com guandu anão favoreceu maior sincronismo de 
crescimento entre ambas as espécies. Desta forma, o consórcio pode aumentar os rendimentos das gramíneas, principalmente pelo fornecimento de $\mathrm{N}$ ao solo por meio da FBN.

Nem sempre haverá influência do consórcio sobre as características das plantas, principalmente, em curto prazo. Isso foi observado para LF, CF e NP de cana-de-açúcar, aos oito meses de idade, que não apresentaram efeito de tratamento. Para a MV, observou-se que a produtividade foi maior no tratamento em monocultivo, pois o estande final de plantas por hectare é maior em relação ao cultivo intercalado em consórcio.

Considerando a oferta total de forragem por hectare, dos três sistemas de cultivo, observou-se que o monocultivo de cana-de-açúcar oferta a maior quantidade de MV por hectare seguido de feijão-guandu em monocultivo (Figura 2). Diante disso, tanto o feijãoguandu, quanto a cana-de-açúcar, cultivados em monocultivo, favorecem o manejo, sendo que o feijão-guandu deve ser cultivado somente o necessário para suprir proteína, uma vez que apresenta baixa produtividade. O feijão-guandu ainda apresenta a vantagem de ser utilizado como banco de proteína.

O cultivo de cana-de-açúcar, no Brasil, é feito majoritariamente em monocultivo, entretanto, sistemas de cultivo consorciado têm sido testados, mas nem

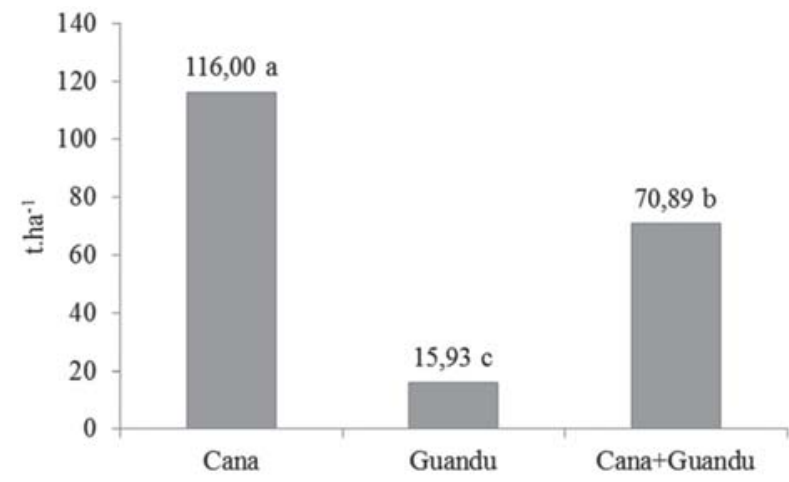

Figura 2 - Oferta de massa verde (t.ha-1 ${ }^{-1}$ de cana-deaçúcar e feijão-guandu cultivados em monocultivo e consorciados. Médias seguidas por letras diferentes na barra, diferem pelo teste Tukey ao nível de $5 \%$ de probabilidade. CV: 14,98\%. Média geral: 67,60 t.ha-1 . sempre os resultados são satisfatórios. Machado e Margarido (2014) constataram que o consórcio de canade-açúcar com diferentes culturas (milho, feijão e mandioca) não influenciou a altura da cana e o Grau Brix. Dantas et al. (2015) observaram que as leguminosas amendoim forrageiro (Arachis pintoi), calopogônio (Calopogonium mucunoides), xiquexique (Crotalaria anagyroides), crotalária júncea (Crotalaria juncea), estilosantes ‘Campo Grande’ (mistura física de sementes de Stylosanthes capitata e S. macrocephala) e guanduanão (Cajanus cajan), introduzidas nas entrelinhas da cana de açúcar, em manejo orgânico, em sistema de consorciação, com semeadura tardia dos adubos verdes, não interferem na produtividade de colmos, produção de açúcar e qualidade do caldo da cana planta e da primeira cana soca.

Futuros estudos, com outros arranjos de espaçamento para o consórcio de cana-de-açúcar com feijão-guandu, são necessários, principalmente para avaliar os efeitos do consórcio a longo prazo, considerando o efeito da liberação de nutrientes e do teor de matéria orgânica fornecidos pelas folhas que caem sobre o solo, além dos restos culturais das plantas de feijão-guandu que poderá beneficiar a rebrota da cana nos anos subsequentes.

Quanto aos atributos da fertilidade do solo, houve influência dos tratamentos apenas para o teor de $\mathrm{Ca}^{2+} \mathrm{e} \mathrm{V}$. Os teores de $\mathrm{Ca}^{2+} \mathrm{e}$ valores de $\mathrm{V}$ foram maiores no tratamento com feijão-guandu em monocultivo (Tabela 4).

De modo geral, as leguminosas possuem elevado teor de Ca no tecido vegetal em razão da reciclagem deste nutriente das camadas mais profundas do solo (Espindola et al., 2006). Devido ao seu sistema radicular pivotante, as leguminosas conseguem extrair nutrientes em profundidade, disponibilizando nas camadas superficiais do solo (Cavalcante et al., 2012). Entretanto, em curto prazo esse efeito nem sempre é percebido. Cultivos sucessivos ao longo dos anos podem aumentar a fertilidade do solo, promovendo incrementos na produtividade da gramínea consorciada com a leguminosa.

O consórcio entre cana-de-açúcar e feijão-guandu não promove, em curto prazo, o aumento dos atributos da fertilidade do solo. O feijão-guandu em monocultivo proporciona aumento de teores de $\mathrm{Ca}$ na camada arável do solo, bem como o aumento da saturação por bases (V). 
Tabela 4 - Atributos da fertilidade do solo em cultivo de cana-de-açúcar e feijão-guandu

\begin{tabular}{|c|c|c|c|c|c|c|c|c|c|}
\hline Tratamento & $\mathrm{pH}$ & $\mathrm{P}$ & $\mathrm{K}$ & $\mathrm{Ca}$ & $\mathrm{Mg}$ & SB & $\mathrm{t}$ & $\mathrm{T}$ & $\mathrm{V}$ \\
\hline & $\mathrm{H}_{2} \mathrm{O}$ & $-\mathrm{m} \xi$ & $1^{-3}$ & \multicolumn{5}{|c|}{$-\mathrm{cmol}_{\mathrm{c}} \mathrm{dm}^{-3}$} & $\%$ \\
\hline Cana & $5,64 a$ & $6,17 a$ & $66,67 a$ & 4,35b & $1,81 \mathrm{a}$ & $6,33 b$ & $9,50 a$ & $9,50 a$ & $67,17 b$ \\
\hline Guandu & 5,69a & $7,40 a$ & $89,33 a$ & $5,05 a$ & 1,89a & $7,31 \mathrm{a}$ & $8,68 a$ & $9,55 a$ & $76,60 \mathrm{a}$ \\
\hline Cana+Guandu & $5,96 a$ & $7,40 \mathrm{a}$ & $86,67 a$ & $4,40 b$ & $2,04 \mathrm{a}$ & $6,51 b$ & $6,51 \mathrm{a}$ & $9,08 \mathrm{a}$ & 71,73ab \\
\hline Média geral & 5,86 & 6,99 & 80,89 & 4,6 & 1,91 & 6,72 & 8,23 & 9,37 & 71,83 \\
\hline
\end{tabular}

Médias seguidas pela mesma letra na coluna não diferem entre si pelo teste Tukey ao nível de 5\% de probabilidade.

\section{CONCLUSÃO}

O cultivo consorciado de cana-de-açúcar e feijãoguandu, no espaçamento de $1 \mathrm{~m}$ entre linhas alternadas, não aumenta a oferta de forragem destas culturas em curto prazo.

\section{AGRADECIMENTOS}

Os autores agradecem à Fundação de Amparo à Pesquisa do Estado de Minas Gerais (FAPEMIG) e ao Conselho Nacional de Pesquisa (CNPq) pelo apoio financeiro e concessão de bolsas.

\section{LITERATURACITADA}

AMBROSANO, E.J.; CANTARELLA, H.; ROSSI, F. et al. Desempenho de adubos verdes e da primeira soqueira de cana-de-açúcar cultivados consorciadamente. Revista Brasileira de Agroecologia, v.8, n.3, 2013.

AZEVEDO, R.L.; RIBEIRO, G.T.; AZEVEDO, C.L.L. Feijão guandu: uma planta multiuso. Revista da FAPESE, v.3, n.2, p.81-86, 2007.

BARCELLOS, A.D.O.; RAMOS, A.K.B.; VILELA, L. et al. Sustentabilidade da produção animal baseada em pastagens consorciadas e no emprego de leguminosas exclusivas, na forma de banco de proteína, nos trópicos brasileiros.

Revista Brasileira de Zootecnia, v.37, suplemento especial, p.51-67, 2008.

CALVO, C.L.; FOLONI, J.S.S.; BRANCALIÃO, S.R. Produtividade de fitomassa e relação $\mathrm{C} / \mathrm{N}$ de monocultivos e consórcios de guandu-anão, milheto e sorgo em três épocas de corte.

Bragantia, v.69, n.1, p.77-86, 2010.
CAVALCANTE, V.S.; SANTOS, V.R.; SANTOS

NETO, A.L. et al. Biomassa e extração de nutrientes por plantas de cobertura. Revista Brasileira de Engenharia Agrícola e Ambiental, v.16, n.5, 2012.

COMPANHIA NACIONAL DE ABASTECIMENTO (CONAB). Acompanhamento da safra brasileira de cana-de-açúcar: safra 2016/2017, v.3, n.2, Segundo levantamento, Brasília, p.1-72, agosto 2016. Disponível em: $<$ http://www.conab.gov.br/>. Acesso em: 24 de agosto de 2016.

DANTAS, R.A.; CARMONA, R.; CARVALHO, A.M. et al. Produção de matéria seca e controle de plantas daninhas por leguminosas consorciadas com cana de açúcar em cultivo orgânico. Pesquisa Agropecuária Brasileira, v.50, n.8, p.681-689, 2015.

EMPRESA BRASILEIRA DE PESQUISA AGROPECUÁRIA - EMBRAPA. Centro Nacional de Pesquisa de Solos. Manual de métodos de análise de solos. 2.ed. Rio de Janeiro, 1997. 212p.

ESPINDOLA, J.A.A.; GUERRA, J.G.M.; PERIN, A. et al. Bananeiras consorciadas com leguminosas herbáceas perenes utilizadas como coberturas vivas. Pesquisa Agropecuária Brasileira, v.41, n.3, p.415-420, 2006.

FERREIRA, D.F. Sisvar: A guide for its bootstrap procedures in multiple comparisons. Ciência e Agrotecnologia, v.38, p.109-112, 2014.

GODOY, R.; BATISTA, L.A.R.; SANTOS, P.M. et al. Avaliação agronômica de linhagens selecionadas de guandu (Cajanus cajan (L.) Millsp). Revista Brasileira de Zootecnia, v.34, n.1, p.7-19, 2005. 
MACHADO, R.; MARGARIDO, L.A.C. Ensaios com sistemas orgânicos de produção para a soca da cana-de-açúcar, utilizando a técnica do plantio intercalar. Cadernos de Agroecologia, v.9, n.4, 2014.

MARQUES, L.F.; BELTRÃO, N.E.M.; VALE, L.S. et al. Consórcio mamona e amendoim: opção para a agricultura familiar. Revista Verde de Agroecologia e Desenvolvimento Sustentável, v.5, n.4, p.222-227, 2010.

NERES, M.A.; CASTAGNARA, D.D.; SILVA, F.B. et al.Características produtivas, estruturais e bromatológicas dos capins Tifton 85 e Piatã e do feijão-guandu cv. Super N, em cultivo singular ou em associação. Ciência Rural, v.42, n.5, p.862-869, 2012.

PARIZ, C.M.; ANDREOTTI, M.; AZENHA, M.V. et al. Produtividade de grãos de milho e massa seca de braquiárias em consórcio no sistema de integração lavoura-pecuária. Ciência Rural, p.875-882, 2011.

PRELLWITZ, W.P.V.; COELHO, F.C. Produtividade de colmos, índice de área foliar e acúmulo de $\mathrm{N}$ na soca de cana-de-açúcar em cultivo intercalar com Crotalaria juncea L. Ceres, v.58, n.6, 2015.
PROVAZI, M.; CAMARGO, L.H.G.; SANTOS, P.M. et al. Descrição botânica de linhagens puras selecionadas de guandu. Revista

Brasileira de Zootecnia, v.36, n.2, p.328334, 2007.

UNIVERSIDADE FEDERAL DE VIÇOSA - UFV. Departamento de Engenharia Agrícola. Estação meteorológica. Dados climáticos. Viçosa, MG: UFV, 1997.

UNIVERSIDADE FEDERAL DE VIÇOSA - UFV. Departamento de Engenharia Agrícola. Estação Climatológica Principal de Viçosa. Boletim meteorológico 2015. Viçosa, 2015.

UNIVERSIDADE FEDERAL DE VIÇOSA - UFV. Departamento de Engenharia Agrícola. Estação Climatológica Principal de Viçosa. Boletim meteorológico 2016. Viçosa, 2016.

VOLTOLINI, T.V.; SILVA, J.G.; SILVA, W.E.D.L. et al. Valor nutritivo de cultivares de cana-deaçúcar sob irrigação. Revista Brasileira de Saúde e Produção Animal, v.13, n.4, 2012.

Recebido para publicação em 13/6/2017 e aprovado em 04/10/2017. 